\title{
UNICEF: produção da adolescência pelo acontecimento ato infracional
}

\section{UNICEF: production of adolescence through the infrational act}

DOI: $10.46814 /$ lajdv2n6-010

Recebimento dos originais: 01/09/2020

Aceitação para publicação: 30/10/2020

\author{
Alanna Caroline Gadelha Alves \\ Psicóloga/UFPA. \\ Endereço: Rua Augusto Correa, 01 (IFCH-UFPA). Guamá, Belém-PA, CEP 66.075-110. \\ E-mail: alanna.cga@gmail.com
}

Flávia Cristina Silveira Lemos

Psicóloga/UNESP. Mestre em Psicologia Social/UNESP. Doutora em História Cultura/UNESP. Pósdoutora em Psicologia/UNESP. Profa Dra associada III em Psicologia Social/UFPA. Bolsista de

Produtividade de Pesquisa/CNPQ-PQ2.

Endereço: Rua Augusto Correa, 01 (IFCH-UFPA). Guamá, Belém-PA, CEP 66.075-110.

E-mail: flaviacslemos@gmail.com

\section{RESUMO}

Este artigo traz algumas análises sobre a produção do ato infracional para o Fundo das Nações Unidas para a Infância (UNICEF), no Brasil como uma prática considerada a partir das noções de risco e perigo e propõe práticas de saber, poder e subjetivação constitutivas do que denomina adolescência autora de ato infracional. Para o UNICEF, há a demanda de um governo das condutas de adolescentes que cometeram atos classificados como infracionais a partir da biopolítica, gestão ligada a um racismo de Estado e de sociedade. A racionalidade do controle social dos processos de desenvolvimento é usada para regular os corpos de adolescentes por meio de uma lógica punitiva, baseada na seletividade das medidas socioeducativas em função de classe social, gênero e raça-etnia.

Palavras-chave: UNICEF, Brasil, Adolescente, Infração, Racismo.

\begin{abstract}
This article brings some analyzes on the production of the infraction for the United Nations Children's Fund (UNICEF), in Brazil as a practice considered from the notions of risk and danger and proposes practices of knowledge, power and subjectivity that constitute calls adolescence the author of an infraction. For UNICEF, there is a demand for a government for the conduct of adolescents who committed acts classified as offenses from biopolitics, a management linked to racism by the State and society. The rationality of social control of development processes is used to regulate the bodies of adolescents through a punitive logic, based on the selectivity of socio-educational measures according to social class, gender and race-ethnicity.
\end{abstract}

Keywords: UNICEF, Brazil, Adolescent, Infringement, Racism. 


\section{INTRODUÇÃO}

Estruturar a adolescência à margem do discurso proposto pela UNICEF é deslocar à produção de conteúdo dos documentos oficiais e normativos legais, para pensar a produção política que a instituição UNICEF propõe. É ir além de um conceito direcionado à adolescência pelos aparatos do desenvolvimento, mas observar as marcas de um grupo específico focalizado na prevenção, controle e cuidado de comportamentos considerados "perigosos" à sociedade. É importante mencionar que o Fundo das Nações Unidas para a Infância (UNICEF), integra o sistema da Organização das Nações Unidas (ONU) e como tal foi instituída em 11 de dezembro de 1946, por decisão unânime da Assembleia Geral, de modo a ser criada no âmbito do pós-segunda guerra mundial para proteção das crianças e adolescentes.

Nessa engrenagem estruturada pela guerra, de consensos e dissensos, a entrada da Unicef no Brasil como agência reguladora, incidiu diretamente as políticas direcionadas para as crianças e adolescentes no Brasil por uma série de dispositivos normativos, seja por meio de Tratados Internacionais assinados pelo Brasil, seja pelas normas inseridas na Constituição Federal de 1998 e Estatuto das Crianças e Adolescentes no Brasil (ECA). Além disso, a importância da UNICEF tem se revelado na formulação e propulsão das teorias de desenvolvimento humano, ao definir a adolescência como "fase", "período" e "fronteira", cujo cuidado, proteção e compromisso são ponto importante para o desenvolvimento do Brasil (SILVA, p.37).

Essa pressão política, implementada desde 1950, data de criação da UNICEF no Brasil é operada por intermédio da produção de cartilhas, relatórios e estudos realizados na esfera da infância e juventude, ou por meio da fiscalização no gerenciamento das metas produzidas em conjunto com as agências regulamentadoras, iniciativa privada e ONG's.

Da análise dos documentos produzidos pela Unicef, destacamos três documentos, a saber: a) Educar ou punir? A realidade da internação de adolescentes em Unidades Socioeducativas no Estado de Pernambuco; b) Trajetórias interrompidas: homicídios na adolescência em Fortaleza e em seis municípios do Ceará e c) Guia municipal de prevenção da violência letal contra adolescentes e jovens. Da leitura destes relatórios pode-se perceber que a adolescência se mantém como uma fase de ruptura entre a infância e preparação da vida adulta. A articulação desse corpo, entendido como lugar de inscrição de acontecimentos, com a história e da integração das práticas discursivas, das relações de poder e das técnicas de subjetivação, estimulam e produzem novas formas de ser, pensar, sentir e agir dentro de uma estrutura delimitada pelo tempo histórico, a saber: a construção do poder pastoral e da teologia econômica. Veja-se: 
Em relação ao conceito de adolescência, o mesmo está relacionado às peculiaridades e diversidades dessa fase da vida em cada sociedade, compreendendo ser um período do desenvolvimento humano caracterizado por transformações múltiplas que estão ligadas ao indivíduo e à cultura a que pertence. (UNICEF, 2012, p.18)

Verificando-se a necessária discussão da pastoral como teologia econômica que serve ao governo dos homens e das coisas na concepção da governamentalidade e do poder disciplinar, a adolescência é marcada pela incapacidade de contenção dos atos de desobediência, de modo que o Estado apropria-se do poder disciplinar como movimento de docilização dos corpos a fim de promover um exercício de poder marcado pelo jogo das normas, estruturadas por dispositivos que possuem sua gênese ontológica na teologia econômica. No cumprimento desta reflexão, o discurso de saber e verdade encontra-se amplamente identificado como técnica de condução das almas na base do Estado como representante dos indivíduos. Nesse passo, a adolescência nos documentos da UNICEF se delineia como "oportunidade", como "desafio", sem deixar de destacar a prática violência letal no Brasil a juventude negra, aos moradores de favela e periferias urbanas, conforme reporta o Guia Municipal de Prevenção da violência letal contra adolescentes e jovens proposto pela Unicef.

Foucault (1994 [1977], p.304) nos adverte que o poder é marcado por "uma relação de forças desigual e relativamente estabilizada, evidentemente isto implica uma diferença de potencialidade entre em cima e em baixo" que se adequam a uma estrutura de coordenação simbiótica que caminha para a formação de uma grade de pontos que se interconectam por linhas de forças horizontais representadas nos micro mecanismos de poder e por forças verticais representadas pelas macro políticas que se direcionam para a construção de modos de subjetivação invadidos por forças políticas, econômicas, sociais, culturais e históricas.

Esses pontos de encontro, essas microfissuras, se revelam como políticas públicas construídas a partir de um padrão do indivíduo, sendo esta colonização teórica filtrada no termo dispositivo que sempre se inscreve dentro de um jogo de poder, ligado à diversas configurações de saber, que a partir dele se orientam e semelhantemente o condicionam. "É isto, o dispositivo: estratégias de relações de forças sustentando tipos de saber, e sustentadas por eles" (Foucault, 1994 [1977], p. 300). Portanto, a somatória das forças desiguais às relações estabilizadas é reconstruída por relações entre opressor e oprimido que se instituem nas relações de poder.

Essa simbiose implica na retratação das relações de poder que podem ser identificadas nas relações de violência vivificadas tanto na construção das políticas públicas quanto no gerenciamento destes corpos proposto pelo Estado como agenciador dos elementos discursivos e não discursivos voltados para o adolescente e para o adolescente que praticou o ato infracional, seja por meio da administração da educação, seja pela implementação de vieses punitivos.Esse chamado do discurso 
estratégico é observado também no planejamento normativo, na medida em que a concepção de violência praticada por uma criança e um adolescente muda pela simples inferência da idade. Neste ponto a criança, em geral, é anunciada como vítima, seja qual for a sua conduta, ao passo que o adolescente que praticou ato infracional é analisado de forma ambígua, seja como autor ou coparticipante dos seus comportamentos. Ao final, o adulto que transgride uma norma, ainda que jovem, é taxado como um elemento perigoso para a sociedade e plenamente capaz por qualquer ato cometido (UNICEF, 2012, p.20).

Esse movimento de "projeção desejável do corpo social e do sujeito" diante de um ponto de historicidade, mantém e origina uma função estratégica acometida de uma funcionalidade que se fixa no tempo. A delimitação do desenvolvimento unicamente pela idade, por si já prefigura uma reinterpretação normativa que justificaria a racionalidade positiva. É de se destacar que para o ECA, a criança se encontra na faixa de 0 (zero) a 11 (onze) anos de idade, a adolescência de 12 (doze) a 17 (dezessete) anos de idade, o jovem pela ONU se enquadra na faixa de 15 (quinze) a 24 (vinte e quatro) anos de idade e pela Secretaria Nacional de Juventude, através da incorporação da noção de adulto jovem, de 15 (quinze) a 29 (vinte e nove) anos.

Há de verificar que a produção de significados que ditam modos e maneiras da relação do sujeito, ou melhor, dos modos e maneiras de pensar, sentir, agir, de se relacionar, são atingidas por forças verticais e horizontais (que podem ser políticas, econômicas, sociais, culturais, históricas) determinando processos de subjetivação, a partir da permanência de um objetivo estratégico. Identificar a natureza dessas relações heterogêneas possibilita delimitar as forças constituintes do dispositivo, na medida em que, uma resposta coletiva sempre é ecoada entre as estratégias do corpo social e do sujeito (ALVES, 2019, p.56).

Esse caminhar conjunto da sobredeterminação funcional e da perpetuação do preenchimento estratégico figuram no conceito de adolescência uma administração de políticas públicas e práticas institucionais que aliam ao fator idade uma gestão de determinadas capacidades que encontram sua latência no saber científico e biológico. Leia-se o ECA que aponta o "fenômeno da puberdade" como viés de passagem da fase infantil para a adulta e a Unicef (2002, p. 10) que se apoia "em diferentes concepções e teorias psicológicas sobre o próprio desenvolvimento humano".

(...) a opção aqui é por uma concepção sistêmica e construtivista do adolescente como um ser em desenvolvimento que, ao mesmo tempo em que preserva sua singularidade, também está em constante interação com seu contexto familiar e social pelo qual é influenciado e também influencia. (...). A adolescência consiste, pois, em um processo de intensas transformações, tanto internas como externas. (...). Por essa razão, considera-se a adolescência como uma etapa do ciclo de vida familiar, uma vez que todos os membros da família mudam juntos e a 
transformação não é apenas do adolescente consigo mesmo, mas também do adolescente em suas relações familiares e sociais. (UNICEF, 2002, p.10)

A família, portanto, para a UNICEF se enlaça ao conceito de adolescência e o integra as relações familiares e sociais trazendo para a adolescência um conceito amplo que se estende para além das meras transformações biológicas. Esse cruzamento de sujeitos que mutuamente percorrem múltiplas mudanças elaboram uma nova funcionalidade do conceito adolescência produzindo um prequestionamento da intencionalidade da estratégia original, de modo a criar uma formatação diferenciada de gestão de políticas públicas que vivenciam uma etapa singular no desenvolvimento do indivíduo adolescente e, consequentemente, do adolescente em conflito com a lei.

\section{ATO INFRACIONAL PARA A UNICEF}

“Aquele menino não era da família, não era da vizinhança, não era da comunidade. Ele não era ninguém" (Diretor de um centro socioeducativo em Fortaleza, Unicef, 2017, p.23). Trinta anos que os adolescentes brasileiros tiveram direito a ter direitos, trinta anos de um movimento de proteção integral da criança e do adolescente, entretanto, o que extraímos dessa fala outrora citada é o reflexo do descaso de atores sociais quando a adolescência vem acompanhada de um ato infracional.

A luta pelo anseio por justiça social, também se mostra como um anseio por liberdade e isso não escapa da área da infância e da juventude. Fazendo um retrospecto do Código Melo Mattos (1927), cujo termo "menores abandonados e menores delinquentes (art. $1^{\circ}$ ) não servia para crianças e adolescentes e do Código de Menores (1979) destinado à situação irregular que criou a categoria do menor carente e do menor com desvio de conduta, o ECA parte de uma concepção inversa e se apresenta com destino à universalidade. Todos são titulares de direitos e por si devem ser garantidos. Instrumentos jurídicos internacionais também foram regulamentados a fim de propor diretrizes para a execução de medidas socioeducativas: Regras Mínimas das Nações Unidas para a Administração da Justiça Juvenil ou Regras de Beijing (1985), as Regras Mínimas das Nações Unidas para os Jovens Privados de Liberdade (1990) e as Diretrizes das Nações Unidas para Administração da Justiça Juvenil (1990).

O Estatuto nasce com essa característica de que toda e qualquer criança tem direito a ter direitos e podem ser resgatados tanto na sociedade, quanto na família, quanto no Estado. Podem ser observadas 31 (trinta e uma) modificações por lei desde o seu início, fora as disposições e atos normativos. Foi uma mudança de paradigmas no que tange ao adolescente, a criança e o jovem enquanto sujeito de direitos. Antes se observava um ambiente de total desproteção que apontava para uma situação de total vulnerabilização. São 30 (trinta) anos de uma trajetória com grande legado em 
defesa do Estatuto, dos mais pobres e em defesa da criança e do adolescente que geraram reflexos inclusive na adoção de um novo olhar para o ato infracional e para o adolescente em conflito com a lei.

Nesse diapasão, o ECA define o ato infracional por "conduta descrita como crime ou contravenção penal” (Lei no 8.069/90, art. 103), “[...] considerada a idade do adolescente à data do fato" (Lei $n^{\circ}$ 8.069/90; art. 104, parágrafo único). As medidas socioeducativas, conforme Lei $\mathrm{n}^{\circ}$ 8.069, art. 112, aplicáveis são: a) advertência; b) obrigação de reparar o dano; c) prestação de serviços à comunidade; d) liberdade assistida; e) inserção em regime de semiliberdade; f) internação em estabelecimento educacional e g) qualquer uma das previstas no art.101, I a VI. Segundo Oliveira (2014, p.92), a medida socioeducativa:

comporta uma dupla condição cuja articulação a torna diferente da simples execução penal:
por um lado, (a) executar uma MSE [medida socioeducativa] é fazer cumprir uma
determinação judicial que impõe a restrição de um direito individual (no caso, a liberdade de
ir e vir) como resposta social legítima a um ato de grave violação do contrato social; por
outro, (b) dada a condição peculiar do adolescente como sujeito em desenvolvimento, menos
maduro que o adulto, a execução deve ter o compromisso de atender aos direitos
fundamentais do adolescente, entre os quais está o de receber tratamento justo, não ofensivo
ou humilhante, pautado em bases legais, minimamente interventivo sobre a subjetividade,
não moralista, ou baseado em expectativas impossíveis de serem atendidas (em relação a tais
aspectos, não há qualquer divergência entre a MSE e uma pena impingida a um adulto); ao
mesmo tempo, a experiência no sistema socioeducativo deveria ser capaz de fazer diferença
na vida do adolescente, provendo-lhe outras linguagens alternativas à infração para se
posicionar diante das condições profundamente adversas nas quais se constrói sua identidade.

Assim, "executar a medida socioeducativa" e perceber a "condição peculiar do adolescente" imporia bases que não fossem ofensivas ou humilhantes, pautadas em bases legais, "minimamente interventivo sobre a subjetividade, não moralista, ou baseado em expectativas impossíveis de serem atendidas", de forma a problematizar o processo de regulação social e econômica diante do ato infracional cometido, pois na medida em que o Estado é responsável por organizar as decisões capazes de gerenciar os processos econômicos como sujeito universal de saber vinculado a uma ordem econômica (FOUCAULT, 2008b, p.237), “a 'oferta' de educação, bem como a de outras políticas públicas, se constitui como uma estratégia de prevenção dos 'riscos' e têm, por fim, a regulação da população, e vem acompanhada de discursos e práticas de segurança" (SILVA, 2011, p. 96).

Logo, Foucault (2008b, p.49) ressalta "a análise da constituição de certo direito da verdade, a partir de uma situação de direito, com a relação direito/verdade encontrando sua manifestação privilegiada no discurso", primordial para a construção da genealogia e fundamental para a investigação dos significantes que incidem pelo discurso da ressocialização do adolescente e da 
verdade a ele vinculada por intermédio das práticas socioeducativas e das falas normativas. Como Silva (2011, p.109) propõe, na modernidade, “é preciso regular para melhor controlar, não mais de forma individualizada, mas do corpo múltiplo, extraindo deste corpo, os seus 'riscos' e as suas 'potencialidades"'. Dessa forma, nutre-se uma série de verdades imbricadas no discurso normativo da ressocialização que falam da adolescência, das práticas da lógica punitiva, do ato infracional e das diretrizes de trabalho.

A liberdade quando associada ao regime liberal, principalmente no que refere a arte de governar desta filosofia política, é multifacetada e recriada a todo instante, de forma que a mesma não é sinônima de um significado imutável e se articula a necessidade do Estado, cujo custo é o discurso de segurança. A mecânica deste cálculo é articular o divergente e o convergente na configuração do assujeitamento das disposições individuais às dos outros, por meio das práticas de ressocialização, sob o discurso do "interesse de todos" projetado na normalização e inclusão do adolescente aos moldes da coletividade (ALVES, 2019, p.109).

Então, a partir do exposto por Foucault (2008b), o perigo e as estratégias de segurança caminham conjuntamente na construção do liberalismo, instaurando uma cultura do medo aliado à gestão do perigo concomitante a restrição da liberdade, pois, aos que oferecem risco retira-se a liberdade em função de uma razão de Estado representativa da Lei. No caso da lógica punitiva do adolescente que cometeu ato infracional, busca-se a todo momento a produção de comportamentos que refletem um comportamento ajustado para com o outro e consigo, cujos parâmetros são instituídos pelos aplicadores de medidas socioeducativas da instituição (ALVES, 2019, p.110).

Nesse ponto, vale rememorar a comparação que Foucault (1997b) faz da cidade com a prisão, pois esta articula uma rede de discursos e práticas que visam um poder de normalização. Dessa forma, o cárcere não pode ser acolhido como um lugar isolado destituído de fragmentos advindos dos discursos de governo, mas está “ligado a toda uma série de outros dispositivos 'carcerários', aparentemente bem diversos - pois se destinam a aliviar, a curvar, a socorrer - mas que tendem todos com ela a exercer um poder de normalização" (FOUCAULT, 1987, p.254).

A “máquina a vapor para rápida correção das meninas e dos meninos", gravura do século XVIII, apresentada por Foucault (2009, p.30/31), já anunciava uma administração sob o corpo masculino e feminino como fonte de disciplina e normalização para a correção dos comportamentos "desviantes", sendo, pois, possível uma análise da anatomia do corpo articulada tanto ao poder disciplinar como à biopolítica na economia liberal, na medida em que, o corpo representa uma potência de assujeitamento do indivíduo à política da normalização (ALVES, 2019, p.111). Essa tecnologia política do corpo, portanto, era aplicada à crianças definidas como "preguiçosas, gulosas, 
indóceis, desobedientes, briguentas, mexeriqueiras, faladoras, sem religião, ou que tenham qualquer defeito" e além, "crianças incorrigíveis" sendo a máquina um vetor de poder de adestramento das meninas e meninos que precisavam ser corrigidos, sendo, pois, as práticas penais "mais como um capítulo da anatomia política do que uma consequência das teorias jurídicas (FOUCAULT, 2009, p.31).

Pensar a ressocialização unicamente pelo viés pedagógico a ela vinculado torna-se uma falácia, na medida em que, a prática educativa associada ao aprisionamento da liberdade configura um caráter prisional ao ato socioeducativo emergido por pareceres, alvarás e atos normativos. Nessa relação, o adolescente ao adentrar na estrutura para ele formulada, ingressa no dilema: cumprir o ato ou manter-se na instituição não se adequando às medidas formuladas pelo PIA. A partir desta díade, o adolescente que outrora estava imerso num contexto social marcado por relações culturais, do meio, da família, do parceiro amoroso move-se para outro contexto no qual o tempo é demarcado pelo território da internação e a proximidade da soltura é marcada pela correção dos comportamentos "em conflito com a lei" iniciando a escrita de uma nova biografia. Por consequência, o objetivo se torna "sair da instituição socioeducativa" e não "modular os meus comportamentos inadequados para iniciar uma nova história no qual o ato infracional não será tomado como uma opção reincidente", dando-se início a um ciclo biopolítico de correção dos corpos (ALVES, 2019, p.112).

Nesse plano de fundo, resistências vão operar para produzir diferenças, pois apesar do objetivo ser formular um plano de atendimento individualizado a própria prática da internalização carrega consigo a prática de igualar, suprimindo a subjetividade da adolescente ali inserida, identificada como aquela em que está em conflito com a lei. Esse governo de alma como dirá Foucault, cria um nível de identificação subjetiva e convida a formação do eu privado a viver no sectarismo da identidade "adolescente que pratica ato infracional", concomitante a perda de linha de força da diferença (ALVES, 2019, p.112).

No Relatório "Educar ou Punir: A realidade da internação de adolescentes em unidades socioeducativas no estado de Pernambuco", há um destaque extraído do XIV Fórum Nacional da Justiça Juvenil de 2013, no qual os magistrados que lidam com a área infracional de uma série de estados, inclusive do Distrito Federal, constituíram como consenso "a ausência de aplicabilidade da lei e de estrutura para executar a socioeducação" (CNJ, 2013, p.1), o que só reafirma esse espaço de internação utilizado como fruto da estrutura de punibilidade do ato infracional, sendo ausente, em sua grande maioria, a evolução do adolescente como sujeito de direitos fundamentais e presente a fragilidade do sistema socioeducativo como meio de reinserção destes adolescentes na sociedade. De acordo com o Relatório "Educar ou Punir: A realidade da internação de adolescentes em unidades 
socioeducativas no estado de Pernambuco", tal ausência de propostas adequadas frente ao ato infracional cometido pelo adolescente "pode estar relacionada ao não acesso dos adolescentes aos direitos, como educação, esporte, lazer e profissionalização, aliado ao contexto de acesso das organizações criminosas a esses adolescentes" (UNICEF, 2017, p.41), por fim, conclui que "antes de cometer um ato infracional, o adolescente tem seus direitos fundamentais violados".

Destarte, a socioeducação é caracterizada pela ação do Estado diante das circunstâncias nas quais o adolescente é responsabilizado pela autoria do ato infracional. A abordagem da socioeducação privilegia a garantia de direitos sobre a sanção, na execução da medida socioeducativa, em consonância com o direito da criança e do adolescente preconizado nos tratados internacionais, na Lei no 8069/1990 e na Lei no 12.594/2012 (OLIVEIRA, 2014).

Assim o ato infracional para o Unicef não se caracteriza como um ato advindo unicamente do adolescente, mas de uma estrutura social que prepara o adolescente para exercer o cometimento do ato típico legal, sendo o Estado o grande propulsor dessa pressão política e de não acolhimento do adolescente que praticou o ato infracional dentro dessa estrutura de não execução adequada da medida socioeducativa. A família, a sociedade e os atores manifestos nesse processo de execução da MSE respondem pela organização do sistema socioeducativo e pela ampliação das normas de proteção, sendo co-responsáveis na garantia de direitos.

\section{POLÍTICAS PÚBLICAS DESENVOLVIDAS PELA UNICEF}

Na seara das políticas públicas temos que ela se refere à uma ordem local cuja construção política é reificada pelos agentes internos e externos de um ponto operacional comum de ação do Estado em um dado território (MULLER \& SUREL, 1988, p. 22). Consequentemente, pensar em uma ótica de neutralidade liberal, perpassa pela incongruência de discurso quando se pensa em política pública e prática judiciária, na medida em que, as mesmas são invadidas por forças que se desdobram dentro de uma estrutura desordenada que comporá uma decisão com eficácia pública e se constrói dentro de uma lógica e racionalidade própria da relação do quadro público (ALVES, 2019, p. 60). De um modo geral, as políticas desenvolvidas pelo Estado caminham sob uma égide poder e saber que se direcionam para os corpos dos apenados, ou melhor, dos adolescentes que praticaram ato infracional, e que são capturados dentro da nossa cultura como objeto de valor e desvalor, dentro do paradoxo de vida como valor e desvalor. Então, a gestão dessa vida é administrada nesse compasso da biopolítica.

Em homo sacer, Agamben (2004) nos diz que o cálculo que o poder faz sobre a vida, é um cálculo muito específico sobre um tipo de vida, não é então aquela vida política, não é a vida do 
homem lúcido, varão, dono do poder, governando a sociedade, mas a vida de zoé, a vida isolada à existência política. Nesse espaço político, coexistem o corpo físico, marcado pelo simples objeto no espaço, e o corpo vivente, o qual demanda a vivência na experiência do corpo dentro do espaço. Este corpo vivente é o objeto de estudo de Foucault, impossível de se isolar, impossível de ser desconsiderado dentro da existência política (ALVES, 2019, p.115). Agamben (2004), ao desenvolver sua teoria, buscou retratar justamente os que estão fora desse âmbito cultural, os excluídos, mas que concomitantemente penetram o âmbito cultural a partir do momento em que se colocam no cálculo do poder do jogo político, enquanto vida a ser manipulada, controlada.

Esse homo sacer (Agamben, 2004), que vaga pela cidade, carrega dentro de si uma vida nua,
uma vida isolada, alheia ao seu próprio modo de existência. Ele não é parte da vida cotidiana
da cidade, mas também não está fora das delimitações da cidade, se mostra integrado ao
entorno dela como ser humano, porém sua existência não permanece integrada a ordem
democrática. O poder político, portanto, ao dar conta da existência desse corpo, permaneceu
no decorrer da história utilizando esta figura e a integrou a estrutura moderna, acoplando à
mulher, ao mendigo, ao refugiado, ao negro, aos adolescentes que praticam ato infracional.
Portanto, percebe-se que, apesar do Estado reconhecer a existência dessas vidas, as mesmas
se excluem da estrutura da sociedade, pela gestão biopolítica (ALVES, 2019, p.116)

Toda biopolítica, nesse jogo de poder, será uma tanatopolítica (AGAMBEN, 2007), nas quais as formas de gestão da vida, assim como as de morte estão orientadas para um inimigo comum, perigoso, cujo governo das condutas, e aqui leia-se as leis e normas, é produzido para gerenciar os corpos dos supostos "inimigos" em defesa da sociedade. Corroborando com esse entendimento, o SINASE possui a disciplina como norte das diretrizes pedagógicas quando articulada à ressocialização para a eficácia da medida socioeducativa, leia-se: "a disciplina deve ser considerada como instrumento norteador do sucesso pedagógico, tornando o ambiente socioeducativo um polo irradiador de cultura e conhecimento e não ser vista apenas como um instrumento de manutenção da ordem institucional” (BRASIL, 2006, p.48).

Esse "fazer crescer, ao mesmo tempo, a docilidade e a utilidade de todos os elementos do sistema" (FOUCAULT, 2009, p.206) correspondente a disciplina, confere a medida socioeducativa uma tarefa de ajustamento para fazer diminuir a 'desutilidade" dos indivíduos, que se encontram em desacordo com a economia do poder. Esta infra-penalidade norteadora das diretrizes pedagógicas representa, pois, uma tecnologia no qual "o fazer crescer a utilidade singular de cada elemento da multiplicidade" demanda "táticas de distribuição, de ajustamento recíproco dos corpos, dos gestos e dos ritmos, de diferenciação das capacidades, de coordenação recíproca em relação a aparelhos ou a tarefas" de modo a administrar as multiplicidades por poderes anônimos e coextensivos a ordem do Estado (FOUCAULT, 2009, p.207-208). 
A segurança socioeducativa, por conseguinte, está atrelada a uma biopolítica da insegurança, pois, ao mesmo tempo em que há a finalidade socioeducativa da adolescente em conflito com a lei, em nome da segurança social, há também um controle do cálculo de vida desse adolescente que não apenas reflete a frouxidão do sistema social como também mantém as condicionantes de falhas da segurança, para que, apesar de "corrigidos" comportamentalmente, tais adolescentes quando ressocializados dificilmente se amolda aos padrões socialmente exigidos, ou mesmo, terão uma possibilidade de mudança das situações que o impunham na condição de prática do ato infracional. Dessa forma, a segurança oferecida pela prática da medida socioeducativa é um dispositivo capaz de produzir subjetividades que se alinham aos objetivos propostos pelo Estado para a manutenção da biopolítica da insegurança (LUSTOSA, 2013).

Esse debate efervescente e tão necessário é encontrado dentro da pressão política operada pela Unicef, e se liga as falas encontradas nos relatórios quando da gestão de participação dos adolescentes, de gerenciar formas de educação, da discussão em relação às formas de superlotação das unidades de internação permanente e provisória e da necessidade de se investir nas medidas socioeducativas em meio aberto por meio de ações de advocacy e avaliação (UNICEF, 2017, p.73). A partir do "Guia Municipal da Prevenção da Violência Letal contra Adolescentes e Jovens" a Unicef elencou políticas que vivenciam uma etapa singular no desenvolvimento pessoal dos adolescentes que praticaram o ato infracional e que visam o gerenciamento das violências produzidas sob os adolescentes estigmatizados pela juventude, pobreza e criminalidade.

Nesse aspecto, a Etapa 01 e constituída por uma arquitetura institucional que se manifesta como uma alternativa a prevenção da violência letal no município implementado por meio da criação do Comitê Gestor. A Etapa 02 se mostra por intermédio de estratégias de sensibilização permeadas pelo envolvimento de atores estratégicos observados no processo de construção da política e nas práticas preventivas. A Etapa 03 já surge com uma proposta de capacitação e formação de gestores e técnicos locais como ponto estratégico da política de intervenção direcionada principalmente pela educação, família, risco, saúde e profissionalização.

A Etapa 04, por sua vez, funciona pela elaboração de um diagnóstico "vai ser desenvolvido tanto com dados oficiais quanto com informações obtidas a partir de consultas e entrevistas com a comunidade" (UNICEF, 2017, p.14). Essa etapa é caracterizada como uma etapa guia pois produz uma determinada normativa a partir de um referencial epistemológico que vai dar uma organização aos discursos apreendidos dos atores imersos no território do adolescente e que datam a dimensão da experiência "real" do problema a ser encontrado. 
A Etapa 05 já se apresenta pela divulgação e criação do Comprev, que nada mais é do que uma comissão de prevenção da violência letal contra adolescentes e jovens. Essa comissão inclui a participação da sociedade no processo de produção de políticas públicas orientadas para a adolescência e caminhará em conjunto com o poder executivo municipal e por organizações sociais e comunitárias que agregam valor a formulação e implementação da política de intervenção (UNICEF, 2017, p.14).

A Etapa 06 já se dará por uma consulta social evidenciada pelo rastreio das prioridades e políticas aplicáveis, a fim de minimizar essa relação do risco social, desenvolvimento de ações de controle dos pobres e internação de crianças e adolescentes "desviados" como resposta padrão do Estado, de modo a desenhar uma nova política de intervenção.

A Etapa 07, encerraria com a elaboração de um plano municipal de prevenção à violência letal. "Nele deverão estar descritas as prioridades finais, as metas a serem cumpridas, como será feita a adequação da política de intervenção aos recursos sociais, políticos e financeiros disponíveis, e de que forma será feita a avaliação e o monitoramento de todo o processo (UNICEF, 2017, p.14)".

Além dessas bases para a formulação de etapas que venham fazer um trabalho de prevenção da adolescência, a metodologia a Unicef, como órgão voltado para a proteção integral da criança e do adolescente, podemos perceber uma série de políticas que compõem o quadro de precaução, cuidado e controle por vieses da produção de cartilhas, relatórios e estudos por meio da administração de metas e metodologias dos indicadores de justiça juvenil desenvolvido pela Unicef em 2006, em Manual para Mensuração de Indicadores de Justiça Juvenil (UNICEF, 2006).

Os indicadores propõem o levantamento de informações nacionais sobre os adolescentes em conflito com a lei, compreendendo que o uso de indicadores-padrão permite comparar a situação em diferentes países; que o processo nacional de coleta de informações sobre Justiça Juvenil engaja as instituições locais, gerando responsabilidades para as mesmas; geram fontes de informação em delegacias, juizados e locais de internação; e, que o rigor na coleta de informações torna maior a utilidade dos resultados (UNICEF, 2017. p.09).

\section{CONSIDERAÇÕES FINAIS}

O estudo da adolescência e do ato infracional deve ser priorizado e não desestimulado, vez que se mostra como matriz de manipulação utilizada pelo corpo social e pelo Estado, na medida em que se destaca enquanto forma de controle e reorientação comportamental. Por efetividade consequencial, independência no que tange a privação e facilidade na combinação de contingências para a emissão do comportamento inadequado, a punição torna-se um atrativo de docilização e utilidade, de modo que se torna natural sua aplicação em detrimento de outras modalidades de aprendizagem comportamental, desconsiderando-se as implicações oriundas deste viés biopolítico. 
A gestão da infância e do ato infracional, como observado na presente pesquisa, foram formatadas pela sociedade por meio de padrões comportamentais repassados de geração a geração advindas de uma memória tanto histórica quanto social, a fim de impor formas de atuação aos indivíduos dentro dos limites culturais e sociais, reprimindo-se condutas inadequadas ao desenvolvimento do Estado. A manipulação gestada na internação reflete uma política tanto de controla da vida, quanto de controle da morte. Os sujeitos da zoé, se mantém, no tempo histórico e cumprem sua funcionalidade social, na medida de seu descarte social na acepção do neoliberalismo.

Desta forma, o direito da criança e do adolescente enquanto instituto sociopolítico atribuiu para si, por meio de normas jurídicas, um movimento de enrijecimento da punição pelo agravamento dos atos infracionais, construindo em seus artigos formas de punição no intuito de reprimir a violência, expressada por comportamentos desviantes. De antemão, o Estado entendido como agência de controle, estende às normas os padrões previamente definidos pelo grupo, com o intuito de afirmar-se socialmente, imbuindo ao ECA o "personagem" de indicar as regras e consequências caso seja praticado um comportamento socialmente não aceito. Importa ressaltar que o primeiro problema observado nesta forma de aplicação da medida socioeducativa é que controlador e controlado raramente encontram-se no mesmo espaço temporal impedindo-se, desta forma, o controle efetivo da aprendizagem pela aplicação da sanção legal.

Por outro viés, a coerção seja fruto de uma construção social reorientada para a sobrevivência como indivíduo adolescente e adolescente infrator, tal forma de intervenção sócio individual deve ser desmistificada enquanto melhor forma de controle comportamental, já que incita a fragilidade do sistema socioeducativo e sua falibilidade quando colocamos como objeto de análise o Estado, a família, a comunidade e a sociedade e revela-se como um reflexo das consequências da utilização indiscriminada da punição, o que nos mostra a evidente necessidade de reforma.

Dessa sorte, a interação entre a Unicef e os atores sociais faz-se necessária uma vez que o ECA ainda se encontra embrutecido por técnicas de controle social voltadas prioritariamente para a internação do adolescente que praticou o ato infracional, fruto do período sócio-histórico em que foi elaborado marcado por intensas repressões; muito embora, atualmente, observe-se um movimento no sentido de propor novas soluções alternativas às medidas socioeducativas de internação, de maneira a gestar uma dicotomia no regramento da medida socioeducativa que ora se mostra extremamente punitiva, ora traça um caminho restaurativo e integracionista.

Há de se destacar que as modificações legislativas não modificaram a estrutura do ECA, os pilares de proteção integral da infância e juventude continuaram. Além de que não foram alterados os princípios e direitos fundamentais, pois os mesmos possuem uma base Constitucional. O Estatuto fez 
o que a Constituição o autorizava a fazer, o Estatuto, portanto, deu vida aos direitos da infância e juventude, ensejando como modificações principais a adoção, a execução de medidas socioeducativas, tendo o SINASE como propulsor da organização do sistema socioeducativo, bem como propiciou a ampliação das normas de proteção. Assim, esse espaço de conhecimento da adolescência potencializado pelo aparato jurídico-discursivo intensificou a mudança de paradigmas da criança e do adolescente enquanto sujeito de direitos.

Assim, o gerenciamento e aplicação das políticas públicas propostas pela Unicef, no que se refere à reforma do sistema socioeducativo brasileiro é interessante na medida em que motiva o jurista, o Estado e o corpo social a afastar-se da perspectiva da imediata internação como mera punição sanção, conduzindo-lhe a uma reflexão que se motiva para além das premissas jurídicas doutrinárias e normativas, de modo a manejar o direito do adolescente que praticou um ato infracional para além da ferramenta de controle social, de modo a estimular conjuntamente com associações civis e outras agências controladoras, o planejamento de contingências favoráveis à produção de comportamentos que levem à prevenção e precaução de atos infracionais, bem como, formular a emissão de comportamentos que possam se manter estáveis, provendo unicidade entre a política socioeducativa e a reestruturação de novas formas de ressocialização do indivíduo, principalmente no que trata da solução de conflitos.

A implementação do plano municipal de prevenção à violência letal, bem como a aplicação da metodologia dos indicadores de justiça juvenil, na presente pesquisa, surge como um exemplo de prática já adotada pelo Brasil, em microesferas, voltada para a humanização do sistema socioeducativo, provendo a ressignificação da punição na medida socioeducativa, tendo em vista que traz outras agências de controle para a construção da melhor medida a ser aplicada ao adolescente em conflito com a lei, propondo um diálogo entre vítima, opressor e Estado, reforçando a proposta da Unicef de criar um ambiente propício à conscientização da sociedade, no que trata da efetividade de outras técnicas que não as fundamentalmente coercitivas.

É claro que outras formas de intervenção poderão ser aplicadas na tentativa de se reorientar o comportamento inadequado, mas faz-se necessária uma predisposição da sociedade e dos juristas na edificação de um sistema socioeducativo e de um direito da infância e juventude que possibilite o desenvolvimento de um diálogo aberto para a formação de juristas capazes de criar mecanismos de modificação estrutural do ordenamento jurídico projetados para a reforma do sistema socioeducativo. 


\section{REFERÊNCIAS}

ALVES, Alanna Caroline Gadelha. Dispositivos jurídicos e percepção de processos de subjetivação em adolescentes que cumprem medidas socioeducativas no CESEF: Um olhar institucional. Dissertação (Mestrado em Direito, Políticas Públicas e Desenvolvimento Regional) Programa de Pós Graduação Stricto Sensu em Direito, Centro Universitário do Estado do Pará, Belém, Pará, 2019.

NOGUEIRA, Thaís de Souza. A relação entre esporte, cultura, lazer e a medida socioeducativa de internação no Centro Socioeducativo Feminino - CESEF/Pará, de 2006 a 2014. Dissertação (Mestrado em Psicologia) - Instituto de Filosofia e Ciências Humanos, Universidade Federal do Pará, Belém, Pará, 2016.

AVELINO, D. P. O Sistema Único de Assistência Social (SUAS) e o Sistema de Justiça. In: OLIVINDO, K. A. F.; ALVES, S. M. C.; ALBUQUERQUE, S. A. Olhares sobre o direito à Assistência Social. Brasília, DF: Fiocruz Brasília; Ministério do Desenvolvimento Social e Combate à Fome, 2015. p. 149-159. Disponível em: <http://www.mds.gov.br/webarquivos/publicacao/assistencia_social/Livros/olhares_sobre_direito_as sistencia_social.pdf>. Acesso em: 25 de maio de 2018.

BRASIL, Lei $\mathbf{n}^{\mathbf{0}} \mathbf{8 . 7 4 2}$, de 7 de dezembro de 1993. Disponível em: https://www.planalto.gov.br/ccivil_03/leis/L8742compliado.htm.

. Política Nacional de Assistência Social PNAS/2004. Norma Operacional Básica NOB/SUAS. Brasília, DF: Ministério do Desenvolvimento Social e Combate à Fome; Secretaria Nacional de Assistência Social, 2004.

. Norma Operacional Básica NOB/SUAS. Brasília: MDS, 2005.

. Resolução no $\mathbf{n}^{\mathbf{0}}$ 119, dispõe sobre o Sistema Nacional de Atendimento Socioeducativo SINASE, Brasília, DF: CONANDA, 2006a.

Resolução n;113, de 19 de abril de 2006, dispõe sobre os parâmetros para a institucionalização e fortalecimento do Sistema de Garantia dos Direitos da Criança e do Adolescente. Brasília: CONANDA, 2006b.

$2006 c$.

Norma Operacional Básica de Recursos Humanos do SUAS. Brasília: MDS,

Resolução no 109, de 11 de novembro de 2009, dispõe sobre a tipificação nacional de serviços socioassistenciais. Diário Oficial da União, Brasília: Conselho Nacional de Assistência Social, 2009.

Orientações Técnicas: Centro de Referência Especializado de Assistência Social CREAS. Brasília: SNAS/MDS, 2011a.

Lei Ordinária no. . 12.435, de 6 de julho de 2011. Altera a Lei no 8742 de 07 de dezembro de 1993, que dispõe sobre a organização da Assistência Social e cria o SUAS. Brasília: MDS, $2011 b$. 
MDS, 2012.

Norma Operacional Básica de Assistência Social - NOB/SUAS, 2012. Brasília:

. Plano Nacional de Atendimento Socioeducativo: diretrizes e eixos operativos para o SINASE. Brasília, DF: Secretaria de Direitos Humanos da Presidência da República, 2013a. Disponível em: <https://www.sdh.gov.br/assuntos/criancas-e-adolescentes/pdf/plano-nacionaldeatendimento-socioeducativo-diretrizes-e-eixos-operativos-para-o-sinase.

Caderno de Orientações Técnicas: Serviço de Medidas Socioeducativas em Meio Aberto. Brasília: Ministério de Desenvolvimento Social e Agrário. Secretaria Nacional de Assistência Social, 2016.

CNJ (Conselho Nacional de Justiça). Em Brasília, Fonajuv debate carências de sistema socioeducativo. Publicado em: 18 ago. 2013. Acesso em: <http://www.cnj.jus.br/noticias/judiciario/26000:em-brasilia-fonajuv-deba-te-carencias-de-sistemasocioeducativo>. Acesso em: 13 de agosto de 2020.

DELUCHEY, Jean François Y Deluchey. Sobre estratégias e dispositivos normativos em Foucault: considerações de método. Revista da Faculdade de Direito UFG, v.40, n.02, p. 175-196, julho/dezembro de 2016. Disponível em:<https://www.revistas.ufg.br/revfd/article/view/44128\&gt;. Acesso em: 01 de julho de 2018>.

FOUCAULT, Michel. A verdade e as formas jurídicas. Rio de Janeiro: NAU, 1996b.

O nascimento da biopolítica. Rio de Janeiro: Martins Fontes, 2008d.

. Vigiar e Punir: a história da violência nas prisões. 32. ed. Petrópolis: Vozes,1987b-

2009.

Genealogia e poder. In:

Microfísica do poder. Rio de Janeiro: Paz e Terra,

$2014 c$.

LEMOS, Flávia Cristina Silveira; SCHEINVAR, Estela; NASCIMENTO, Maria Lívia do. Uma análise do acontecimento "crianças e jovens em risco". Psicol. Soc., Belo Horizonte , v. 26, n. 1, p. 158-164, Apr. 2014 Available from $<$ http://www.scielo.br/scielo.php?script=sci_arttext\&pid=S0102-

$71822014000100017 \& \operatorname{lng}=$ en $\& n r m=$ iso $>$. access on 02 June 2020. https://doi.org/10.1590/S0102-71822014000100017.

LUSTOSA, Patrícia Rocha. Dispositivos Socioeducativos, Biopolítica e Governamentalidade. Belo Horizonte, $\quad$ Setembro, $2013 . \quad$ UFMG. http://www.bibliotecadigital.ufmg.br/dspace/bitstream/handle/1843/BUOS-

9KRFHY/tese_impressa_patricia_lustosa.pdf?sequence=1. Acesso em: 16 de dezembro de 2018.

OLIVEIRA, M. C. S. L. de. Da medida ao atendimento socioeducativo: implicações conceituais e éticas. In: PAIVA, I. L.; SOUZA, C.; RODRIGUES, D. B. (Org.). Justiça Juvenil: teoria e prática no sistema socioeducativo. Natal, RN: EDUFRN, 2014.

SILVA, Ana Lúcia Santos da. Interrogação práticas do UNICEF para os adolescentes no Brasil, 2011. 144f. Dissertação (Mestrado em Psicologia) - Instituto de Filosofia e Ciências Humanos, Universidade Federal do Pará, Belém, Pará, 2011. 